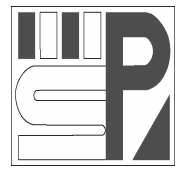

Science Press
Journal of Arid Land

2012, 4(1): 105-112

doi: 10.3724/SP.J.1227.2012.00105

jal.xjegi.com; www.chinasciencejournal.com

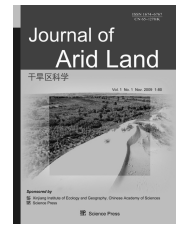

\title{
Spatio-temporal pattern and changes of evapotran- spiration in arid Central Asia and Xinjiang of China
}

\author{
Xi CHEN ${ }^{1 *}$, BaiLian LI ${ }^{1,2}$, Qin LI $^{3}$, JunLi LI ${ }^{1}$, Saparnov ABDULLA ${ }^{4}$ \\ ${ }^{1}$ State Key Laboratory of Desert and Oasis Ecology, Sino-US International Center of Ecology in Arid Land, Xinjiang Institute of \\ Ecology and Geography, Chinese Academy of Sciences, Urumqi 830011, China; \\ ${ }^{2}$ Ecological Complexity and Modeling Laboratory, Department of Botany and Plant Sciences, University of California, Riverside \\ CA 92521-0124, USA; \\ ${ }^{3}$ University of Jinan, Jinan 250022, China; \\ ${ }^{4}$ U.U.Uspanov Kazakh Research Institute of Soil Science and Agrichemistry, Ministry of Agriculture of Kazakhstan, Almaty \\ 050060, Kazakhstan
}

\begin{abstract}
Accurate inversion of land surface evapotranspiration (ET) in arid areas is of great significance for understanding global eco-hydrological process and exploring the spatio-temporal variation and ecological response of water resources. It is also important in the functional evaluation of regional water cycle and water balance, as well as the rational allocation and management of water resources. This study, based on model validation analysis at varied scales in five Central Asian countries and China's Xinjiang, developed an appropriate approach for ET inversion in arid lands. The actual ET during growing seasons of the study area was defined, and the changes in water participating in evaporation in regional water cycle were then educed. The results show the simulation error of SEBS (Surface Energy Balance System) model under cloud amount consideration was 1.34\% at 30-m spatial scale, $2.75 \%$ at $1-\mathrm{km}$ spatial scale and $6.37 \%$ at $4-\mathrm{km}$ spatial scale. ET inversion for 1980-2007 applying SEBS model in the study area indicates: (1) the evaporation depth (May-September) by land types descends in the order of waters $(660.24 \mathrm{~mm})>$ cultivated land $(464.66 \mathrm{~mm})>$ woodland $(388.44 \mathrm{~mm})>$ urbanized land $(168.16 \mathrm{~mm})>$ grassland $(160.48 \mathrm{~mm})>$ unused land $(83.08 \mathrm{~mm})$; and (2) ET during the 2005 growing season in Xinjiang and Central Asia was $2,168.68 \times 10^{8} \mathrm{~m}^{3}$ (with an evaporation/precipitation ratio of 1.05 ) and $9,741.03 \times 10^{8} \mathrm{~m}^{3}$ (with an evaporation/precipitation ratio of 1.4), respectively. The results unveiled the spatio-temporal variation rules of ET process in arid areas, providing a reference for further research on the water cycle and water balance in similar arid regions.
\end{abstract}

Keywords: Evapotranspiration (ET); arid areas; SEBS model; remote sensing; Central Asia; Xinjiang of China

Arid areas are among the regions which are most sensitive to global change. Central Asia, which accounts for one third of the world's arid areas, has become a hotspot for global change research. Issues concerning water resources remain to be the focus of environment and ecological studies in these regions. As the ultimate way to water consumption in arid inland water cycle, evapotranspiration (ET) is the most influential factor in maintaining a balance in regional water and energy levels (Cui, 2005; Jiang, 2006; Cheng, 2007). Accurately estimating the spatial and temporal variation of land surface ET is beneficial to adequately understanding the hydrological cycle and energy balance, as well as evaluating the functions of regional water cycle and water balance. To uncover the mechanism of its effects, too, is crucial for ensuring ecological water use, improving the productivity of ecosystems, preventing environmental degradation, and eventually achieving sustainable and renewable use of water cycle (Liu, 2004, 2006; Willem, 2006, 2008).

ET is the combination of soil and plant moistures in their respective processes of evaporation and transpiration. It physically involves air turbulence exchanges near the ground surface and vapor-heat exchanges

Received 2011-10-15; accepted 2011-11-25

*Corresponding author: Xi CHEN (E-mail: chenxi@ms.xjb.ac.cn) 
between vegetation and atmosphere, being closely related to soil water movement and the physiological activity of plants (Si, 2003; Qiu, 2006). Under the context of such increasing concerns as global warming and freshwater shortage, ET research is deepening and has had an integral role in some major international research projects, including International Hydrology Plan (IHP), International Geosphere and Biosphere Program (IGBP), United Nations Environment Program (UNEP), and Global Energy and Water Cycle Experiment (GEWEX) (Yu, 2006). As much as $90 \%$ of the precipitation in arid areas returns into the atmosphere through ET (Guo and Cheng, 2004; Guo, 2005), being coupled with exchanges of land surface substances and energy. On account of the complicated water cycle and energy balance processes that are brought in, the accurate estimate of land surface ET has become an important topic in hydrological, climatological and environmental researches.

ET inversion has evolved from the traditional patch-based methodologies of temperature, radiation or a combination of both (Penman Equation, (Priestly and Taylor, 1972)) to the agro-ecosystem-based model in soil-vegetation-atmosphere continuum (SPAC), and then to the region-based SEBAL (Surface Energy Balance Algorithms for Land) model using remote sensing. Expanding scales and improving accuracy are realized (Le, 2001; Zhang, 2002; Nishida, 2003). Due to the complexity of ET process in arid areas, however, current research on ET pattern under different arid land types is not matured, merely concentrating in potential evaporation (observed pan evaporation data). But huge differences exist between actual ET and potential evaporation. This paper aims to probe into the inversion of actual ET process and discuss the impact of spatio-temporal pattern and changes.

\section{Study area and method}

Situated in the hinterland of the Eurasian Continent, the study area includes five Central Asian countries, i.e. Kazakhstan, Uzbekistan, Kyrgyzstan, Turkmenistan, and Tajikistan, and China's Xinjiang (Fig. 1). Average annual precipitation is scarce and variable, with $90 \%$ occurring in the short summer months. Diurnal and seasonal variations in temperature are also distinct.

The topography is high in the southeast and low in the northwest. The Pamir regions of Tajikistan and

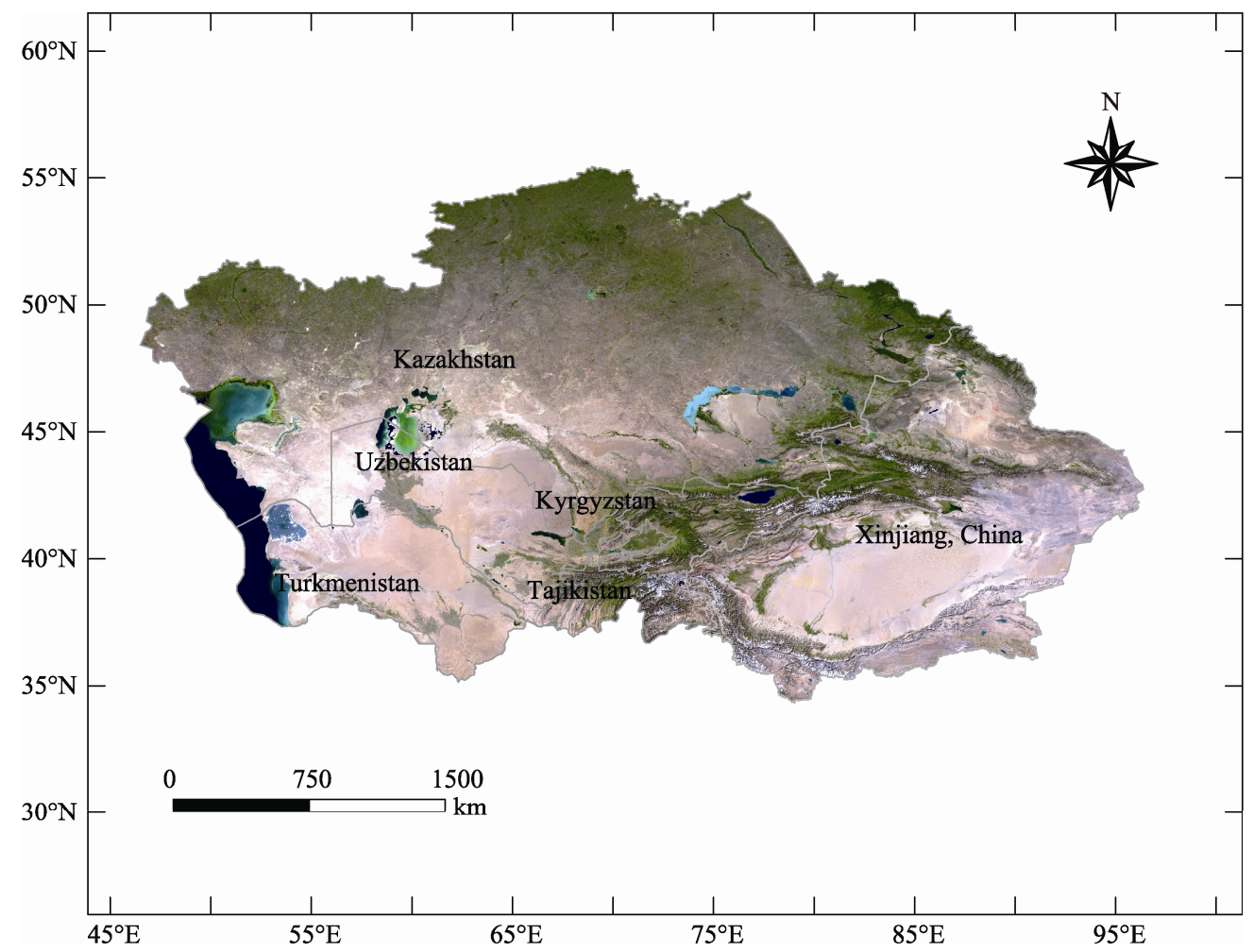

Fig. 1 Map of the five Central Asian countries and Xinjiang of China 
western Kyrgyzstan feature steep mountains, with an altitude of 4,000-5,000 m. The Karagiye Depression near the Caspian Sea in western Kazakhstan is $132 \mathrm{~m}$ below sea level at its lowest point. This vast stretch of land is characterized by deserts and oases at 200-400 $\mathrm{m}$ asl, hills and grasslands at $300-500 \mathrm{~m}$ asl, and eastern mountainous areas at about $1,000 \mathrm{~m}$ asl. Central Asia boasts the most spectacular mountains in the temperate zone, with large tracts of arid desert and interweaving valleys and oases at their feet. In Kazakhstan, grasslands are $300 \mathrm{~m}$ asl, lying on the 1,200-km long Kazakh hills and the 630-km long Turgay Valley. Betpak-Dala, a transitional zone between grassland, semi-desert and desert, sits in the midst of northern platforms and hills and southern deserts. In Xinjiang, mountains and basins are arranged in a staggered manner, the Altai Mountains in the north and the Kunlun Mountains in the south, with the Tianshan Mountains spanning through in the middle. Located between the Tianshan and Kunlun mountains, the $530,000-\mathrm{km}^{2}$ Tarim Basin is the largest of its kind in China. In the central part of the basin is the $330,000-\mathrm{km}^{2}$ Taklimakan Desert, which comes as China's largest and the world's second largest shifting sand desert. Also present is the Tarim River, China's longest inland river. The Turpan Basin in eastern Xinjiang is $154 \mathrm{~m}$ below sea level, making it the lowest point in the country (Zhang, 2006; Chen, 2008).

The southeastern mountains in these regions block the warm, moist air from the Indian and Pacific Oceans, fostering a typical continental climate that features: (1) rare precipitation and extreme aridity. The average annual precipitation is below $300 \mathrm{~mm}$, and it is $75-100 \mathrm{~mm}$ near the Aral Sea and Turkmenistan deserts, and 1,000 mm approximately in the mountains. On the southwestern slope of the Fergana Mountains, precipitation is up to $2,000 \mathrm{~mm}$. But there are also mountainous regions with less precipitation than deserts, such as the $60 \mathrm{~mm}$ recorded in Pamir; (2) abundant sunlight and intense evaporation. The annual solar radiation received can be $130.97-170.31 \mathrm{~W} / \mathrm{m}^{2}$. In Turkmenistan, it reaches $209.26 \mathrm{~W} / \mathrm{m}^{2}$. The dry air and high temperatures bring on a substantial potential for evaporation. In the Amu Darya delta, annual evaporation is up to $1,798 \mathrm{~mm}$, which is 21 times larger than the precipitation here; and (3) radical tem- perature variations. Fluctuation in daily temperatures can be $20-30^{\circ} \mathrm{C}$. The recorded highest value in Pamir is $40^{\circ} \mathrm{C}$. The average temperature stands between $26^{\circ} \mathrm{C}$ and $32^{\circ} \mathrm{C}$ in July, and ascends from $-20^{\circ} \mathrm{C}$ in the north to $20^{\circ} \mathrm{C}$ in the south in January.

\subsection{Data collection}

For the inversion of spatio-temporal ET pattern during 1980-2005 in Central Asia, this paper analyzed three periods (1980, 1990 and 2005, respectively) of remote sensing image data for the study area, among which the data of year 1980 and 1990 were collected from NOAA-AVHRR at $4 \mathrm{~km} \times 4 \mathrm{~km}$ scale and the data of 2005 were based on MODIS $1 \mathrm{~km}^{2}$. TM $(30 \mathrm{~m} \times 30$ $\mathrm{m})$ was then applied to model validation.

Meteorological data in Xinjiang was provided by the Chinese National Meteorological Information Center. A total of 99 weather stations supplied the data of maximum and minimum temperatures specific to the year, month, day and hour, in addition to sunshine duration, wind speed, dew point temperature and small-pan evaporation. The temperature and precipitation data from 154 stations during the period of 18792003 in Central Asia was offered by National Snow and Ice Data Center. For the sake of regional meteorological interpolation, another 3 Russian stations were added. The total number of weather stations in the study area then came up to 256 .

\subsection{SEBS model}

The Surface Energy Balance System (SEBS) model, proposed by $\mathrm{Su}$ (2000), uses a remote sensing approach to calculate evaporation. The calculation of sensible heat flux $(H)$ and latent heat flux $(\lambda E)$ takes into account such indices as wind speed $(u)$ under extreme dry and wet conditions, aerodynamic resistance $\left(r_{a}\right)$ and near-surface potential temperature $\left(\theta_{0}\right)$.

The model comprises four main theoretical aspects: (1) processing of remote sensing images for physical surface parameters, such as albedo rate, emissivity, temperature, and vegetation cover; (2) establishment of a heat transfer roughness model; (3) utilization of Bulk Atmospheric Similarity (BAS) to determine friction speed, sensible heat flux and Obukhov stability; and (4) use of the Surface Energy Balance Index (SEBI) to calculate evaporation ratio.

The SEBS model was originally designed to simu- 
late ET in Europe, where the surface is evenly covered by low vegetation and bears moderate topographic relief and where advection effects are absent. In the arid Central Asia, however, terrain undulation ranges from $-155 \mathrm{~m}$ to 7,233 $\mathrm{m}$, with the Tianshan Mountains running through. Apart from that, sparse vegetation, little precipitation and strong advection effects are all predominating factors. On the basis of land use and land cover data from the 1980s to 2004, and by inputting data for different land types and months published by Land Data Assimilation System (LDAS) of the United States, vegetation height $(h)$, momentum roughness $\left(z_{0 m}\right)$ and zero-plane displacement $\left(d_{0}\right)$ at various spatio-temporal scales of the study area were put forward (Zhan, 2005; Li, 2007).

\subsection{Validation and accuracy assessment}

The validation of ET model simulation in this paper was conducted at both point and surface scales:

(1) Fukang National Field Scientific Observation and Research Station for Desert Ecosystems $\left(44^{\circ} 17^{\prime} \mathrm{N}\right.$, $87^{\circ} 56^{\prime} \mathrm{E}$; $475 \mathrm{~m}$ asl), was selected for point verification. The station is seated on the alluvial fans at the northern slope of the Tianshan Mountains and the southern edge of the Gurbantunggut Desert. Vegetation is represented by Chenopodiaceae $(\mathrm{Xu}$ and $\mathrm{Li}$, 2005). Continental arid climate dominates the place. The temperature is hot and dry in the summer and cold in the winter. The average annual temperature is $6.6^{\circ} \mathrm{C}$, the average annual precipitation is $224.91 \mathrm{~mm}$, and annual potential evaporation is $2,200 \mathrm{~mm}$. The station has storage of relevant eddy covariance data and long-term meteorological observations, which facilitates verification accuracy. The data from 2005 and 2007 were chosen for analysis.

Based on the observational record by eddy correlation instruments and automatic weather stations in growing season from 2005 (April to October), ten-day measured data were compared with LST-albedo model (MODIS $1 \mathrm{~km}^{2}$ ) simulated ET, SEBS model (MODIS $1 \mathrm{~km}^{2}$ ) simulated ET, SEBS model (MODIS $1 \mathrm{~km}^{2}$ ) simulated ET, reference crop ET and corresponding meteorological data. The first ten-day energy balance closure rates for each month of 2005 growing season as recorded by eddy correlation instruments were $89.78 \%, 90.10 \%, 87.53 \%, 92.71 \%, 90.76 \%, 76.4 \%$ and $72.97 \%$, respectively; and the non-closure rates ranged from $7 \%$ to $28 \%$, indicating that these eddy covariance data were reasonable and could be used as standard measurements for validation practice. By analysis, a relatively high correlation value of $94 \%$ was obtained between reference crop ET and pan evaporation data; the value fluctuated with changes in temperature and gave little preference to precipitation considerations. Measured data displayed a strong convergence with LST-albedo model simulated ET and SEBS model simulated ET, correlation coefficients being $79 \%$ and $80 \%$, respectively, and average simulation errors being $16.90 \%$ and $14.86 \%$, respectively. With an overall consideration for the impact of precipitation and temperature, the correlation coefficients of measured data, LST-albedo model simulated ET and SEBS model simulated ET were respectively $89 \%, 82 \%$ and $67 \%$ between precipitation, and respectively $46 \%, 33 \%$ and $62 \%$ between temperature, indicating that precipitation could be the determinant factor for ET under certain arid climate conditions.

The simulation of SEBAL model and SEBS model based on ETM+ images were verified using 2007 eddy covariance observational data, bringing out a diurnal ET as their respective inversion results. Validation of the selected simulation results from May 24, June 25, July 11 and September 13 revealed an energy closure rate of $77.85 \%, 89.87 \%, 85.35 \%$ and $96.87 \%$, respectively, the average error for SEBS simulation being $10.65 \%$ and that for SEBAL simulation being $14.90 \%$, indicating that the data were effective and reliable.

Point validation shows that under the presence of the SEBS model, the simulation error was $14.86 \%$ and $10.65 \%$ at $1 \mathrm{~km}$ and $30 \mathrm{~m}$ scale, respectively;

(2) The Yanqi Basin was selected for scale validation. The diamond-shaped basin is located in the Bayingoleng Mongolian autonomous prefecture of Xinjiang, with a terrain tilted from northwest to southeast. The area of its watershed is $7,384.79 \mathrm{~km}^{2}$ and it is, at its lowest point, home to China's largest inland freshwater lake, Bosten Lake. The data from May and September of 2003 were used for ET simulation validation. A water balance analysis indicated: the actual ET totaled $3.820 \times 10^{8} \mathrm{~m}^{3}$ in May and $3.077 \times 10^{8} \mathrm{~m}^{3}$ in September. Cloud algorithm was adopted for the calculation of monthly ET, and the relative error (simulation accuracy to actual ET) had been controlled within $6.42 \%$, which significantly improved the simulation 
accuracy of ET model at month span. Given the consideration of cloud amount, the average relative error of SEBS model was $6.37 \%, 2.75 \%$ and $1.34 \%$ at $4-\mathrm{km}$, $1-\mathrm{km}$ and $30-\mathrm{m}$ spatial scale, respectively.

\section{Results and Discussion}

\subsection{SEBS model results}

The monthly ET simulation results by SEBS model, based on the period from April to October in 2005, are shown in Fig. 2. For the sake of analysis, the study area was divided into six regions according to territory boders (Fig. 3); and the total area and ET of six classified land types, i.e. cultivated land, woodland, grassland, waters, urbanized land, and unused land were given for the total ET of all respective regions.

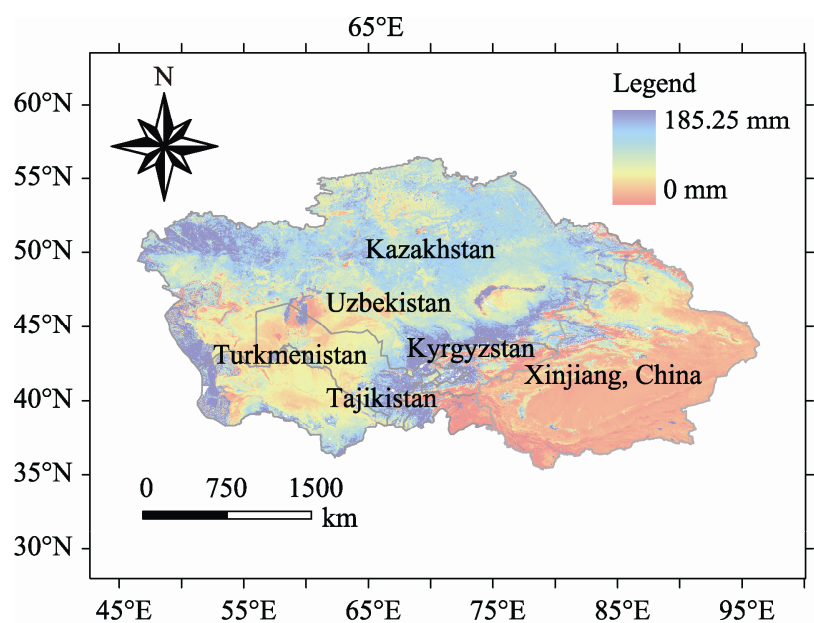

(a) April

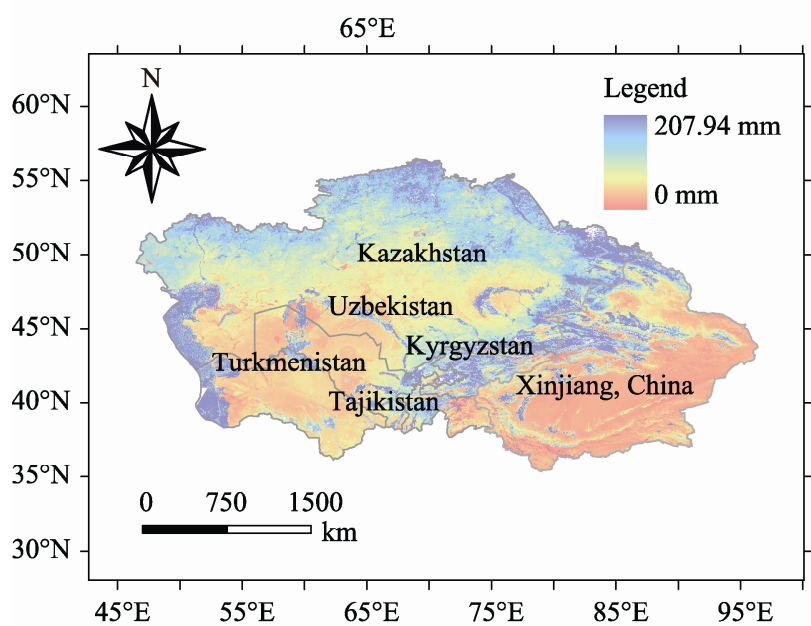

(c) August
During the growing season of April-October, the maximum monthly ET occurred in May, being up to $2,060 \times 10^{8} \mathrm{~m}^{3}$, and a minimum value of $1,230 \times 10^{8} \mathrm{~m}^{3}$ appeared in October, with waters and bare soil taking the lead as main ET contributors (Fig. 4). With regard to evaporation depth, the maximum values for all months came from waters, being at around $100 \mathrm{~mm}$, which was close to the evaporation capacity of the studied area (pan records); the second largest value was for cultivated land, whose underlying surface could be considered as a single homogeneous one, and it approached that of the reference crop with sufficient irrigation while lowered as irrigation water reduced; the values for the rest land types receded in the order of woodland $>$ grassland $>$ unused land.

The spatial changes in monthly ET were illustrated

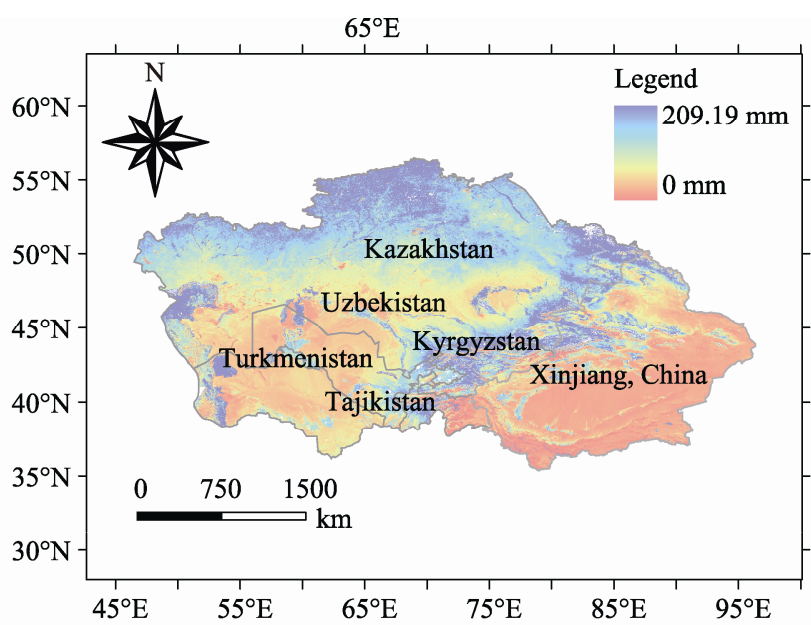

(b) June

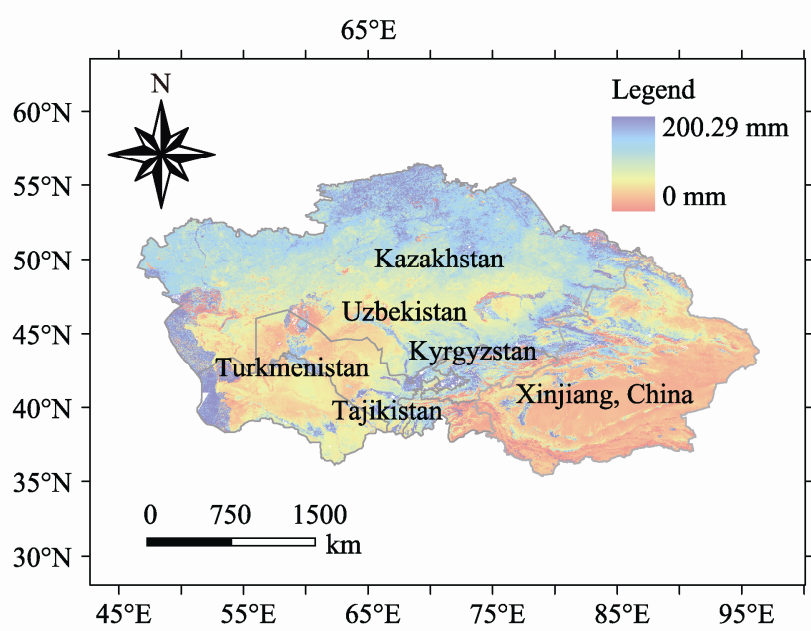

(d) October

Fig. 2 The spatial pattern of monthly ET for April-October, 2005 by SEBS model simulation 


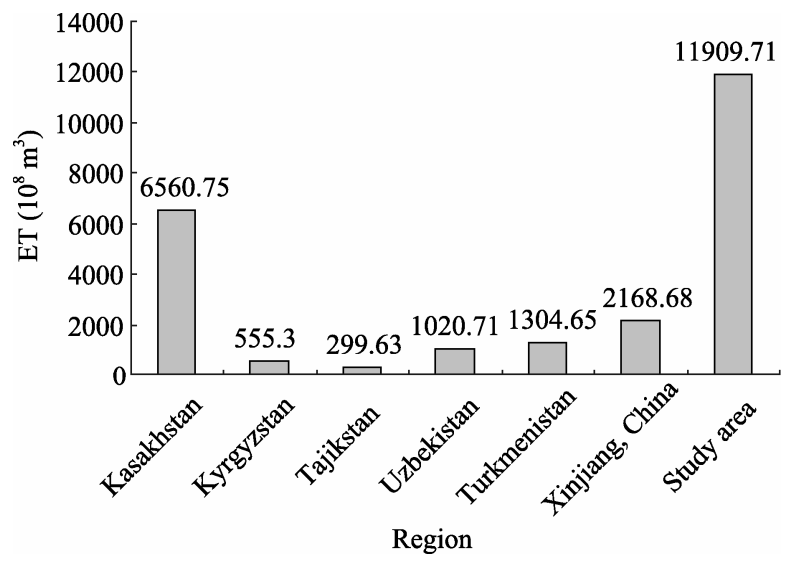

Fig. 3 The total of ET for April-October, 2005 in different studies regions

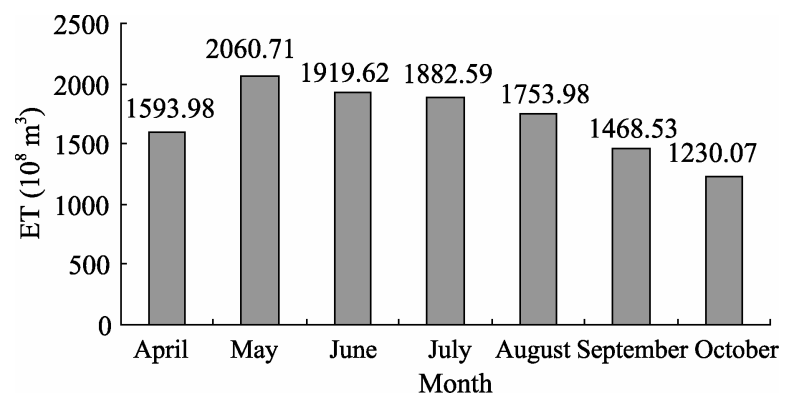

Fig. 4 The total of ET in different months of 2005

by Fig. 2, which shows: (1) For bare land, especially in deserts and Gobi surfaces seen in the Tarim and Junggar basins of Xinjiang, ET remained to be at relatively low rates, less than $50 \mathrm{~mm}$ in all months; while the values increased to about $100 \mathrm{~mm}$ for Altay Mountain forests, Yili alpine meadows, and the oasis farmlands at northern Tianshan Mountains, Yarkand river basin and the middle reaches of Aksu River basin; (2) In Kazakhstan, ET seasonal changes were distributed in a ribbon pattern. Except in the southern Rennes and Dabaersuji deserts, and the Karakum Desert along Aral Sea coasts and the Ayinkum Desert where the ET was $0-50 \mathrm{~mm}$, the ET for the remainder of the region (north of $46^{\circ} \mathrm{N}$ ) was $50 \mathrm{~mm}$ to $150 \mathrm{~mm}$, and water evaporation could reach above $200 \mathrm{~mm}$; (3) Being affected by the Karakum Desert, the ET for bare lands in most of western Uzbekistan and Turkmenistan was 0-50 $\mathrm{mm}$, and about $100 \mathrm{~mm}$ for cultivated lands bodering Kyrgyzstan and Tajikistan in the east; (4) The monthly ET for the majority parts of Kyrgyzstan and Tajikistan maintained to be around $50 \mathrm{~mm}$ during growing seasons; grasslands and cultivated lands dominated western Tajikistan, where ET was about 80 $\mathrm{mm}$ and fluctuated within the range of $20-30 \mathrm{~mm}$ for the unused lands in the east of the country (Fig. 2).

\subsection{Evaporation depth analysis}

As simulated, the total evaporation depth in the study area for May-September of 1980, 1990 and 2005 are shown in Tables 1, 2 and 3.

The average evaporation depths for the regions in the tables were obtained by multiplying the weight

Table 1 The evaporation depths for different studied regions by land types during May-September, 1980

\begin{tabular}{|c|c|c|c|c|c|c|c|}
\hline \multirow{2}{*}{ Region } & Cultivated land & Woodland & Grassland & Waters & Urbanized land & Unused land & Average \\
\hline & \multicolumn{7}{|c|}{$(\mathrm{mm})$} \\
\hline Kasakhstan & 475.72 & 390.57 & 159.60 & 700.57 & 225.41 & 81.45 & 179.97 \\
\hline Kyrgyzstan & 483.72 & 417.64 & 218.76 & 654.23 & 299.42 & 108.99 & 225.46 \\
\hline Tajikstan & 460.43 & 423.99 & 168.90 & 673.86 & 250.06 & 98.13 & 161.08 \\
\hline Uzbekistan & 473.11 & 382.85 & 157.34 & 744.40 & 153.92 & 79.42 & 148.27 \\
\hline Turkmenistan & 389.52 & 352.05 & 125.09 & 721.48 & 117.47 & 67.68 & 164.58 \\
\hline Xinjiang, China & 483.76 & 390.11 & 115.14 & 846.74 & 127.18 & 69.80 & 99.20 \\
\hline Total for the study area & 475.99 & 392.07 & 150.78 & 711.47 & 171.92 & 75.98 & 154.55 \\
\hline
\end{tabular}

Table 2 The evaporation depths for different studied regions by land types during May-September, 1990

\begin{tabular}{|c|c|c|c|c|c|c|c|}
\hline \multirow{2}{*}{ Region } & Cultivated land & Woodland & Grassland & Waters & Urbanized land & Unused Land & Average \\
\hline & \multicolumn{7}{|c|}{$(\mathrm{mm})$} \\
\hline Kasakhstan & 466.26 & 388.44 & 167.74 & 696.82 & 132.89 & 87.26 & 185.32 \\
\hline Kyrgyzstan & 475.32 & 422.18 & 214.17 & 619.32 & 272.57 & 114.03 & 221.06 \\
\hline Tajikstan & 453.17 & 405.26 & 161.62 & 657.52 & 230.69 & 98.86 & 155.61 \\
\hline Uzbekistan & 434.43 & 353.97 & 135.65 & 739.71 & 82.83 & 75.48 & 138.46 \\
\hline Turkmenistan & 361.06 & 339.90 & 123.92 & 712.79 & 78.11 & 72.31 & 166.62 \\
\hline Xinjiang, China & 479.12 & 391.11 & 124.30 & 834.64 & 122.26 & 71.18 & 103.58 \\
\hline Total for the study area & 465.67 & 390.23 & 155.81 & 705.31 & 135.03 & 79.16 & 157.55 \\
\hline
\end{tabular}


Table 3 The evaporation depths for different studied regions by land types during May-September, 2005

\begin{tabular}{|c|c|c|c|c|c|c|c|}
\hline \multirow{2}{*}{ Region } & Cultivated land & Woodland & Grassland & Waters & Urbanized land & Unused Land & Average \\
\hline & \multicolumn{7}{|c|}{$(\mathrm{mm})$} \\
\hline Kasakhstan & 451.87 & 376.11 & 176.00 & 554.77 & 245.22 & 102.22 & 177.68 \\
\hline Kyrgyzstan & 507.81 & 440.70 & 221.91 & 506.99 & 291.33 & 122.73 & 223.17 \\
\hline Tajikstan & 446.05 & 410.68 & 192.48 & 537.67 & 229.02 & 117.64 & 172.40 \\
\hline Uzbekistan & 418.19 & 343.55 & 168.35 & 598.32 & 187.02 & 99.80 & 165.18 \\
\hline Turkmenistan & 420.53 & 330.07 & 140.42 & 570.60 & 134.30 & 81.06 & 165.57 \\
\hline Xinjiang, China & 480.05 & 398.07 & 149.90 & 647.65 & 169.68 & 84.72 & 105.20 \\
\hline Total for the study area & 452.33 & 383.01 & 174.85 & 563.93 & 197.53 & 94.11 & 156.71 \\
\hline
\end{tabular}

(the ratio of the area of each land type to the area of the region that it goes under) and corresponding evaporation depth, with values divided by 100 ; the average evaporation depths for the land types in all regions were obtained by multiplying the weight (the ratio of the area of each land type in the region to the area of the land type in the study area that it belongs to) and corresponding evaporation depth.

The results indicate that the average evaporation depth for the study area in May-September of 1980, 1990 and 2005 was $154.55 \mathrm{~mm}, 157.55 \mathrm{~mm}$ and $156.71 \mathrm{~mm}$, respectively; and the average evaporation depth for the land types in the same study periods was in the order of waters $(660.24 \mathrm{~mm})>$ cultivated land $(464.66 \mathrm{~mm})>$ woodland $(388.44 \mathrm{~mm})>$ urbanized land $(168.16 \mathrm{~mm})>$ grassland $(160.48 \mathrm{~mm})>$ average value $(156.27 \mathrm{~mm})>$ unused land $(83.08 \mathrm{~mm})$.

\section{Conclusions}

In surface water cycle, the ET has been an element that should deserve the minutest estimation. In arid areas particularly, the application of remote sensing in quantitative inversion of surface ET has presented itself as a hotspot as well as a challenge. The spatio-temporal pattern of ET for various surface condi-

\section{References}

Chen X. 2008. Land Use and Land Cover Change of Arid Land in China. Beijing: Science Press.

Cheng Y F, Wang G X, Xi H Y, et al. 2007. Middle reaches of Heihe River plain area in the recent 35 a study on changes of land surface evapotranspiration. Glaciology and Cryopedology, 293: 406-412.

Cui Y L, Xu Y X, Shao J L, et al. 2005. Using remote sensing method for surface steaming method in Yellow River Delta and its relationship with underlying surface. Earth Science Frontiers: tions in the five Central Asian Countries and Xinjiang of China over the past nearly 30 years was probed into, and major influencing factors as well as the status of the water cycle were also discussed. The conclusions are as follows: (1) Cloud algorithm was adopted for the calculation of monthly ET, and the relative error (simulation accuracy to actual ET) had been controlled within $6.42 \%$, which significantly improved the simulation accuracy of ET model at month span. (2) The maximum monthly ET occurred in May, and a minimum value appeared in October, with waters and bare soil taking the lead as main ET contributors; the total ET for May-September of 1980, 1990 and 2005 was $8,960.64 \times 10^{8} \mathrm{~m}^{3}, 9,134.37 \times 10^{8} \mathrm{~m}^{3}$ and $9,085 \times 10^{8}$ $\mathrm{m}^{3}$, respectively. The study confirms that the use of remote sensing techniques is effective in researching spatio-temporal variations of ET in arid areas on a long-term scale.

\section{Acknowledgement}

This research was supported by the National Natural Science Foundation of China (40730633 and 40571030). The authors would like to thank the researchers and staff of the Soil Institute and Institute of Botany in Kazakhstan and Uzbekistan, and the Water Institute of Uzbekistan for their support during field work.

Special Issue: 160-164.

Guo X Y, Cheng G D. 2004. Application of remote sensing technology to advances in research of land surface evapotranspiration. Progress in Earth Science, 21: 107-114.

Guo X Y. 2005. Distribution of evapotranspiration over Heihe River basin using remote sensing method. Progress in Natural Science, 1510: 1266-1270.

Jiang H, Liu Z H, Tang J, et al. 2006. Remote sensing technology in the evaporation study on the estimation of progress. Application 
Technology of Soil and Water Conservation, 3: 37-39.

Le J, Shafiqul I. 2001. Estimation of surface evaporation map over southern Great Plains using remote sensing data. Water Resources Research, 37(2): 329-340.

Liu J M, Wang Z, Diao Y W. 2006. Distributed model and its application in simulating watershed evapotranspiration and validation. Journal of Applied Ecology, 171: 45-50.

Liu S M. 2004. Based on the complementary principle of comparison of regional evapotranspiration estimation model. Geography, 593: $331-340$.

Nishida K, Nemani R, Glassy J M, et al. 2003. Development of an evapotranspiration index from Aqua/MODIS for monitoring surface moisture status. IEEE Transactions on Geoscience and Remote Sensing, 41(21): 493-501.

Priestley C H B, Taylor R J. 1972. On the assessment of surface heat flux and evaporation using large scale parameters. Monthly Weather Review, 100: 81-92.

Qiu G, Shi P, Wang L. 2006. Theoretical analysis of a remotely measureable soil evaporation transfer coefficient. Remote Sensing of Environment, 101: 390-398.

Si X L, Yang Z Y, Yang Z L. 2003. Regional synthetic evapotranspiration calculation method. Hydrology, 234: 17-21.

$\mathrm{Su}$ Z. 2000. Remote sensing of land use and vegetation for mesoscale hydrological studies. International Journal of Remote Sensing, 21(2):
213-233.

Willem W V, Frank V, Jan F, et al. 2005. Estimation evapotanspiration of European forestes from NOAA-imagery at satellite overpass time: towards an operational processing chain for integrated optical and thermal sensor data products. Remote Sensing of Environment, 96: 256-276.

Willem W V, Frank V, Van D, et al. 2006. Soil moisture retrievalusing thermalinertia, determined with visible and thermal spaceborne data, validated for European forests. Remote Sensing of Environment, 101: 299-314.

Willem W V, Frank V, Jan F, et al. 2008. Assessment of evapotranspiration and soil moisture content across different scales of observation. Sensors, 8: 70-117.

$\mathrm{Xu} \mathrm{H,} \mathrm{Li} \mathrm{Y.} \mathrm{2005.} \mathrm{Three} \mathrm{kinds} \mathrm{of} \mathrm{desert} \mathrm{shrub} \mathrm{of} \mathrm{the} \mathrm{water} \mathrm{policy} \mathrm{and}$ related physiological performance. Acta Botanica Sinica, 257: 1309-1316.

Yu G R, Sun X M. 2006. Principles of Flux Measurement in Terrestrial Ecosystems. Beijing: Higher Education Press.

Zhang R H, Sun X M, Zhu Z L, et al. 2002. Based on differential thermal inertia surface evaporation of remote sensing information model and its validation in Shapotou area, Gansu province. Science in China: Series D, 3212: 1041-1050.

Zhang X W, Zhang J B. 2006. Xinjiang Meteorological Manual. Beijing: Meteorological Press. 